\title{
Use of triadimefon to control white pine blister rust
}

\author{
by Jean A. Bérubé ${ }^{1}$
}

White pine seedlings were treated with triadimefon two weeks prior to natural inoculation with Cronartium ribicola and were observed for two growth seasons. During the second growth season in the greenhouse the incidence of blister rust symptoms was $70.8 \%$ for the untreated controls, whereas only $3.8 \%$ of the treated seedlings showed symptoms of blister rust. Triadimefon offers effective protection against white pine blister rust infection and would enable the production of bare root seedlings in areas prone to blister rust infection.
Du triadimefon a été appliqué sur des semis de pin blanc deux semaines avant une inoculation naturelle de Cronartium ribicola. Les semis furent observés par la suite pendant deux saisons de croissance. Au cours de la deuxième saison de croissance en serre, l'incidence des symptômes de la rouille vésiculeuse a atteint $70.8 \%$ pour les témoins non-traités, alors que seulement $3.8 \%$ des semis traités avaient des symptômes de la rouille vésiculeuse. Le triadimefon offre une protection efficace contre les infections de la rouille vésiculeuse du pin blanc et pourrait permettre la production de semis à racines nues dans les zones assujetties aux infections de la rouille vésiculeuse.

\section{Introduction}

White pine (Pinus strobus $\mathrm{L}$.) is highly susceptible to white pine blister rust (WPBR) caused by Cronartium ribicola J.C. Fischer. Since the accidental introduction of this disease in the early 1900's (Piché 1917), white pine blister rust has become the major limiting factor in the natural and artificial regeneration of white pine (Pomerleau 1932; Plourde, et al. 1991), especially in Newfoundland where WPBR incidence is around 32\% (Bérubé 1996). Damp cold weather common in the Atlantic provinces favors disease development making seedlings and young saplings most susceptible to lethal infection.

A systemic fungicide effective against $C$. ribicola would be a useful tool in producing seedlings free of WPBR and in the management of young white pine. Greenhouse tests by Johnson et al. (1992) indicated that sugar pine (P. lambertiana Dougl.) seedlings sprayed with triadimefon and benodanil three weeks before C. ribicola inoculation were well protected from WPBR needle spots, with triadimefon showing residual protection for up to six months.

The objective of this study was to determine the efficacy of triadimefon to control white pine blister rust cankers. Control of cankers is essential for operational use of the fungicide.

\section{Methods}

One hundred and thirty-two seedlings divided in four groups of 33 were sprayed two weeks prior to inoculation with 1000 $\mathrm{mL}$ of 640 ppm mixture of triadimefon (Bayleton ${ }^{\circledR}$, Bayer Inc. Etobicoke, Ontario) using a Mastercraft Lawn Sprayer and similarly, 132 seedlings divided in four groups of 33 were used as controls. The seedlings were naturally inoculated with $C$. ribicola by placing them under infected Ribes spp. bushes in September 1994. Seedlings were left outdoors until December 1994, then moved to a greenhouse in January 1995 to expedite

${ }^{1}$ Canadian Forest Service, Newfoundland and Labrador region, Natural Resources Canada, Bldg. 304 Pleasantville, P.O. Box 6028, St. John's, Newfoundland, Canada A1C 5X8.

Present address: Ressources naturelles Canada, Service canadien des forêts, Région du Québec, 1055 rue du P.E.P.S., C.P. 3800, Sainte-Foy, QC, G1V 4C7 development and expression of blister rust symptoms. WPBR develops slowly taking months for needle spots and many years for cankers to appear. Seedlings were checked and counted for needle spots in May 1995. The seedlings were then stored outdoors again in December 1995 and returned to the greenhouse in February 1996 to expedite canker expression. Final data were collected in March 1996, during the second greenhouse growth season following inoculation with blister rust. The data were analyzed using a t-test in Sigma Plot 3.0 with four repeats per treatment.

\section{Results}

In 1995, seven months after inoculation, none of the 132 Bayleton sprayed seedlings showed blister rust spots while 83 of the $132(63 \%)$ control seedlings showed at least one infection spot. One year after inoculation, the spotted seedlings expressed canker symptoms. In March 1996 during the second greenhouse growth season $70.8 \%$ of the control seedlings showed incidence of blister rust symptoms (Table 1). The infected control seedlings were at various stages of disease development with $39.4 \%$ exhibiting numerous needle spots, $55 \%$ exhibiting blisters (Fig. 1), cankers, stem swelling, heavy resin oozing and dying. Another $16.8 \%$ had already died from blister rust infection. In contrast, only $3.8 \%$ of the treated seedlings were infected and then only needle spots were observed. Cankers, blisters or swellings were not observed on treated seedlings.

Table 1. Incidence of blister rust symptoms on white pine seedlings sprayed with triadimefon after two growth seawsons

\begin{tabular}{lccc}
\hline & \multicolumn{3}{c}{ Percent incidence and standard deviation } \\
\cline { 2 - 4 } & Controls & Treated & $\boldsymbol{P}$ values \\
\hline No symptoms & $29.2 \% \pm 10.6$ & $96.2 \% \pm 4.8$ & 0.00002 \\
Numerous needle spot & $39.4 \% \pm 21.9$ & $3.8 \% \pm 4.6$ & 0.018 \\
Resin oozing & $8.4 \% \pm 4.6$ & 0 & 0.01 \\
Canker & $48.6 \% \pm 14.0$ & 0 & 0.0003 \\
Blisters & $16.2 \% \pm 10.1$ & 0 & 0.017 \\
Dying & $6.9 \% \pm 2.9$ & 0 & 0.003 \\
Dead & $16.8 \% \pm 9.3$ & 0 & 0.038 \\
Total infected & $70.8 \pm 10.6$ & $3.8 \% \pm 4.6$ & 0.00002 \\
\hline
\end{tabular}




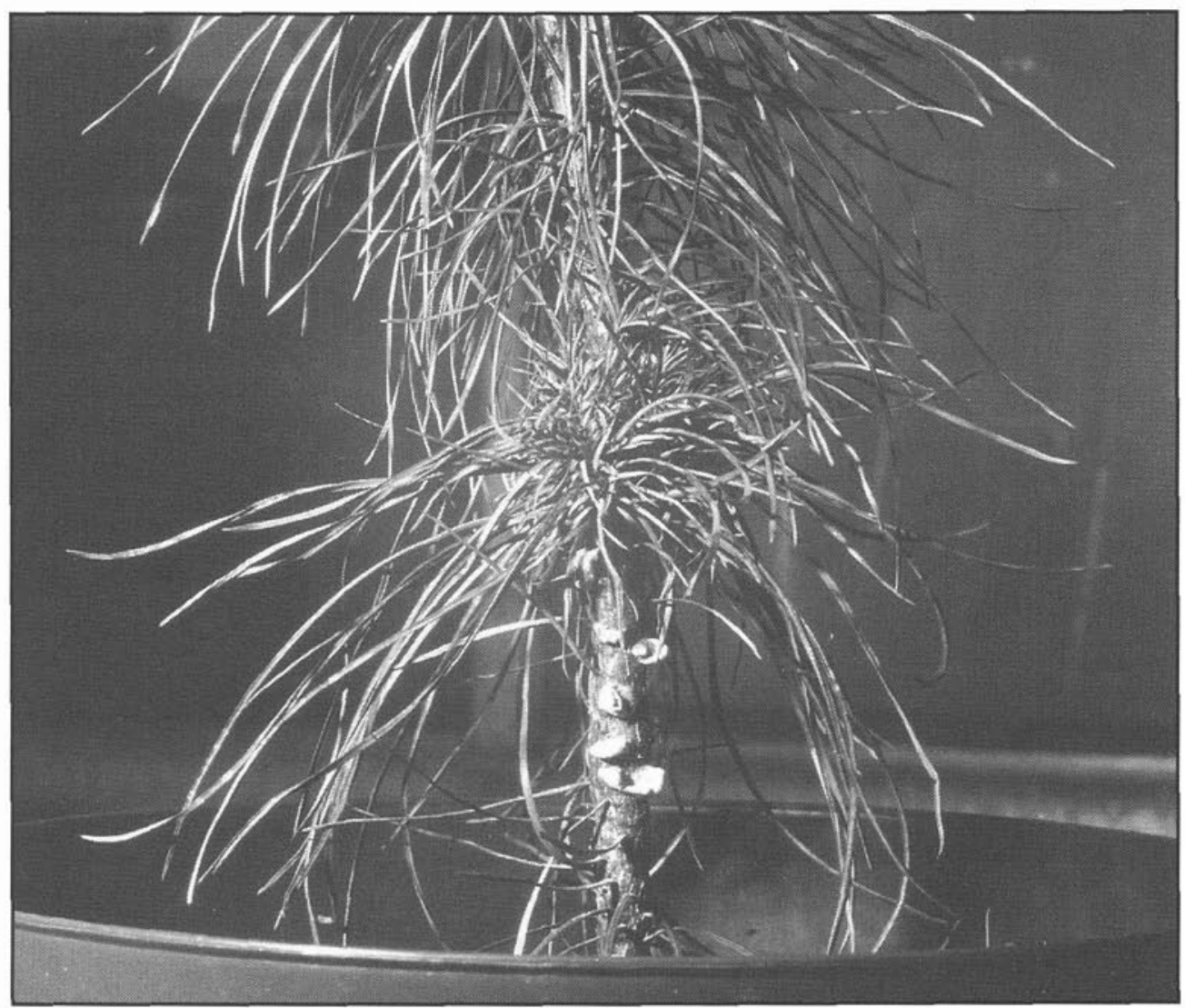

Fig. 1. Canker and blisters on the stem of a control white pine seedling infected Cronartium ribicola.

\section{Discussion}

Triadimefon caused a significant reduction in the incidence of WPBR on white pine seedlings and is a suitable candidate for the control of WPBR cankers in nurseries.

This study confirms the usefulness of needle spots used by Johnson et al. (1992) as indicators for evaluating the incidence of WPBR infection. Seventy-six percent of control seedlings that expressed needle spots later developed cankers after two growth seasons. However, our results showed that treated seedlings exhibited needle spots but no canker development later, indicating that experiments have to continue until full expression of symptoms.

The use of triadimefon enables the production of disease-free three-year-old white pine seedlings in areas such as Newfoundland and the Maritimes where it is currently difficult because ecological conditions favor blister rust.

In addition, applying triadimefon in the field for the first five years after planting might provide an effective way to control lethal cankers on the stem. It is usually during the first five years in the field that lethal infections occur. Annual treatment for five years may be environmentally acceptable and effective in controlling lethal cankers.

\section{Acknowledgment}

The author would like to thank C. Carroll and G.C. Carew for technical assistance, and R.G. West for reviewing the manuscript.

\section{References}

Bérubé, J.A. 1996. Incidence of white pine blister rust in Newfoundland. Submitted to The Forestry Chronicle.

Johnson, D.R., B.B. Kinloch and A.H. McCain. 1992. Triadimefon controls white pine blister rust on sugar pine in a greenhouse test. TreePlanter's Notes: 43: 7-10.

Piché, G.C. 1917. Notes sur la rouille vésiculeuse du pin blanc. Min. des Terres et Forêts. Province de Québec. Circ. 1: 1-10.

Plourde, A., A. Lavallée and A. Corriveau. 1991. White pine blister rust in Quebec: past, present and future. pp. 397-402 In Proceedings of the IUFRO Rust of Pine Working Party Conference. Y. Hiratsuka, J.K. Samoil, P.V. Blenis, P.E. Crane and B.L. Laishley editors. For. Can., Northwest Reg. Edmonton, Alberta. Inf. Rep. Nor-X-317.

Pomerleau, R. 1932. État actuel de la rouille vésiculeuse du pin blanc dans la province de Québec. Soc. Qué. Prot. Plantes. Rap. 23 and 24. 